\title{
Familial recurrence risks for multiple sclerosis in Australia
}

\author{
C O'Gorman, ${ }^{1,2}$ S Freeman, ${ }^{1}$ B V Taylor, ${ }^{3,4}$ H Butzkueven, 5,6,7 \\ Australian and New Zealand MS Genetics Consortium (ANZgene), S A Broadley, ${ }^{1,2}$
}

${ }^{1}$ School of Medicine, Gold Coast Campus, Griffith University, Queensland, Australia

${ }^{2}$ Department of Neurology, Gold Coast Hospital, Southport,

Queensland, Australia

${ }^{3}$ Menzies Research Institute, University of Tasmania,

Tasmania, Australia

${ }^{4}$ Department of Neurology,

Royal Hobart Hospital, Hobart,

Tasmania, Australia

${ }^{5}$ Howard Florey Institute, University of Melbourne,

Victoria, Australia

${ }^{6}$ Department of Medicine and

Neurology, University of

Melbourne, Melbourne, Victoria,

Australia

${ }^{7}$ Department of Neurology,

University of Melbourne,

Melbourne, Victoria, Australia

Correspondence to

Simon A Broadley, School of

Medicine, Gold Coast Campus,

Griffith University, OLD 4222,

Australia;

simon.broadley@griffith.edu.au

Received 24 October 2010 Revised 28 March 2011

Accepted 30 March 2011

Published Online First

7 May 2011

\section{ABSTRACT}

Background Genetic susceptibility to multiple sclerosis (MS) has been recognised for many years. Considerable data exist from the northern hemisphere regarding the familial recurrence risks for MS, but there are few data for the southern hemisphere and regions at lower latitude such as Australia. To investigate the interaction between environmental and genetic causative factors in MS, the authors undertook a familial recurrence risk study in three latitudinally distinct regions of Australia. Methods Immediate and extended family pedigrees have been collected for three cohorts of people with MS in Queensland, Victoria and Tasmania spanning $15^{\circ}$ of latitude. Age of onset data from Queensland were utilised to estimate age-adjusted recurrence rates. Results Recurrence risks in Australia were significantly lower than in studies from northern hemisphere populations. The age-adjusted risk for siblings across Australia was $2.13 \%$ compared with $3.5 \%$ for the northern hemisphere. A similar pattern was seen for other relatives. The risks to relatives were proportional to the population risks for each site, and hence the sibling recurrence-risk ratio $\left(\lambda_{s}\right)$ was similar across all sites. Discussion The familial recurrence risk of MS in Australia is lower than in previously reported studies. This is directly related to the lower population prevalence of MS. The overall genetic susceptibility in Australia as measured by the $\lambda_{s}$ is similar to the northern hemisphere, suggesting that the difference in population risk is explained largely by environmental factors rather than by genetic admixture.

\section{INTRODUCTION}

A genetic susceptibility to multiple sclerosis (MS), the prototypical central nervous system autoimmune disease, has been evident for over 50 years. The first genetic association (HLA) was described in the 1970s. ${ }^{1}$ Early work established a possible genetic basis for susceptibility ${ }^{2}$ and extensive investigation of familial cases has followed. Investigation of twins, ${ }^{3}$ familial risk, ${ }^{4}$ conjugal $\mathrm{MS},{ }^{5}$ adoptive first-degree relatives ${ }^{6}$ and half sibs of patients with $\mathrm{MS}^{7}$ have collectively suggested that multiple genes play a role in susceptibility to MS.

A measure of the genetic susceptibility for a disease is given by the sibling recurrence-risk ratio or $\lambda_{s}{ }^{8}$ This is calculated by dividing the risk for siblings by the population risk (population prevalence). For MS this figure is 20 to $40 .{ }^{9}$ Recent genomewide association studies have now confirmed upwards of 20 susceptibility genes in MS. ${ }^{10}$

As well as this background genetic predisposition, there is strong evidence for a number of environmental factors in determining susceptibility to MS. These include smoking, latitude (an effect which is likely to be related to available sunlight and relative vitamin $\mathrm{D}$ deficiency) and possibly the Epstein-Barr virus. ${ }^{11}$ Australia is historically a nation of intermediate prevalence for MS by comparison with North America and northern Europe, ${ }^{12}$ with a strong association between prevalence of MS and latitude-prevalence increasing from Northern Queensland to Tasmania by more than sixfold. ${ }^{13}$

It has been noted by casual observers that the frequency of familial MS in Australia is not as high as that reported for northern hemisphere countries of largely European heritage. This of course would be expected with the lower background prevalence reflecting lower environmental risks. However, there may be an altered genetic risk due to a greater admixture of genes with up to $10 \%$ of the population being of Asian descent (2006 Census data, http://www.censusdata.abs.gov.au, accessed 2 August 2010).

To date, there has been no systematic survey of the familial risk of MS in Australia or any other mid- to low-latitude location. With the aim of identifying the scale of genetic risk and to provide accurate recurrence risk data for patients with MS in Australia, we have conducted a systematic survey of familial concurrence in various relative groups in three cohorts from centres in Australia which span the latitudinal depth of the country. We have compared these risks with existing data from the northern hemisphere.

\section{METHODS}

\section{Setting}

This study was conducted through MS Clinics at three sites in Australia: Gold Coast, Queensland; Melbourne, Victoria; and Hobart, Tasmania. These clinics provide neurological services specifically for people with MS covering South-East Queensland, northern New South Wales, much of Victoria and Tasmania.

\section{Subjects}

MS clinic attendees at the three sites were invited to participate in the study.

Diagnosis of the proband was made following neurologist assessment using the Poser criteria for 'definite' and 'lab-supported probable' disease,$^{14}$ and, since their introduction, the McDonald and revised McDonald criteria. ${ }^{15} 16$ For affected relatives in Queensland and Tasmania, diagnostic confirmation was undertaken using the above criteria where possible, but where relatives were geographically 
distant or deceased, the diagnosis was made through confirmation by a general practitioner or examination of available medical records. Where no records were available, a diagnosis was determined by one of the study neurologists based on the history and details given by surviving relatives. In the latter instance, only subjects with classical histories for MS were included. For the Victorian data, diagnostic confirmation was not systematically sought for affected relatives.

The study was designed to accommodate only one proband per family. Where multiple possible cases within one family were identified, the first to attend the treating clinic was designated as the proband for that family.

All subjects, probands and affected relatives (where diagnostic confirmation was sought), gave informed written consent to inclusion in the study.

\section{Data collection}

Data for Queensland and Tasmania were collected using a structured and standardised patient completed questionnaire followed by a personal or telephone interview to clarify areas of uncertainty. Information regarding the date of birth, sex and affection status for parents and siblings was requested. In addition, information regarding total number and number of affected other relatives, including offspring, grandparents, nieces/nephews, aunts/uncles and first cousins, was requested from each proband. Contact details of affected relatives were obtained and used to seek diagnostic confirmation. Probands were requested to contact other family members to garner information about their extended family; anecdotally, mothers were most frequently utilised. Data for Victoria were collected systematically, in person, as part of ongoing genetic studies ${ }^{17}$ and only included information on parent and sibling numbers. Affection status was assigned as either case or non-case.

Adoptees, half-sibs, half-aunts/uncles and non-full cousins were excluded.

Ethics approval for the study was obtained from the relevant local human research ethics committee for each site.

\section{Population prevalence}

In order to estimate $\lambda_{s}$, it is necessary to have contemporary accurate regional population prevalence data. With the exception of Tasmania, the most recent prevalence studies in Australia were undertaken in the 1980s. Repeated studies in Tasmania have indicated a significant increase in MS prevalence over the past 50 years, ${ }^{18}$ which echoes findings in other studies from around the world. We have therefore utilised prevalence data obtained in 2006 based on numbers of scripts for $\beta$-interferon/ glatiramer acetate within each region ( $\mathrm{P}$ Klein, personal communication). This analysis gave estimates of prevalence for MS of 47.3/100 000 in Queensland, 84.6/100 000 in Victoria and $122.0 / 100000$ in Tasmania. Although subject to a number of approximations, the estimate for Tasmania was accurate to within $2.6 \%$ when compared with formal prevalence data (actual prevalence 125.2/100.000). ${ }^{18}$

\section{Analysis}

Crude recurrence risks were calculated for all categories of relative by simply dividing the number of affected relatives by the total number of relatives. Age-adjusted lifetime risks were calculated for siblings and parents using the prior age of onset approach and unmodified Strömgren method. ${ }^{19}$ The cumulative age-at-onset distribution was calculated from clinical records of 527 patients held within the Gold Coast MS database (table 1).

It is noted that this distribution is similar to previously published data for Australia, ${ }^{20}$ North America ${ }^{21}$ and northern
Table 1 Cumulative age-of-onset data for Queensland patients

\begin{tabular}{lccc}
\hline $\begin{array}{l}\text { Age range } \\
\text { (years) }\end{array}$ & Frequency & Percentage & $\begin{array}{l}\text { Cummulative } \\
\text { percentage }\end{array}$ \\
\hline $1-9$ & 1 & 0.2 & 0.2 \\
$10-19$ & 10 & 1.9 & 2.1 \\
$20-29$ & 87 & 16.5 & 18.6 \\
$30-39$ & 176 & 33.4 & 52.0 \\
$40-49$ & 165 & 31.3 & 83.3 \\
$50-59$ & 74 & 14.0 & 97.3 \\
$60-69$ & 13 & 2.5 & 99.8 \\
$70-79$ & 1 & 0.2 & 100.0 \\
$80+$ & 0 & 0.0 & 100.0 \\
\hline
\end{tabular}

Europe. $^{22}$ This method of age adjustment accommodates the increased risk of developing MS in family members who have not yet reached the age of maximum risk. The assumptions that the age of onset of relatives is the same as that of probands, and that the pattern of familial recurrence is predictive of recurrence in the future, are consistent with previous findings. ${ }^{23}$

Where age data were incomplete, estimated age based on average age for siblings or mean difference in age between proband and parents was used within families. There was no significant difference $(p>0.05)$ in the figures obtained when these estimated data were included or omitted.

\section{RESULTS}

There were 1837 probands recruited across the three sites. Overall, the ascertainment rate was $93 \%$ of potential participants, with 575/609 Queensland, 941/953 Victorian and 321/ 398 Tasmanian probands consenting to take part in the study. Basic demographic data for these cases are given in table 2. More than $97 \%$ of cases were Caucasian. These data indicate that the populations studied are typical of cross-sectional cohorts of patients with MS in Australia and elsewhere. ${ }^{20} 22$

The crude and, where calculable, age-adjusted risks for each category of relative at each of the three sites and collectively for Australia are given in table 3 . It is evident that the crude risks for the differing categories of relative fall with decreasing degrees of relatedness in each of the cohorts and overall, with the exception of cousins.

These data give a sibling risk of $2.13 \%$ (95\% CI $1.56 \%$ to $2.90 \%$ ) for Australia. This figure is lower than previously reported age-adjusted figures for the UK, $3.8 \%{ }^{24}$ and Canada, $3.6 \%{ }^{6}$ This is in keeping with the lower prevalence of MS in Australia. A similar pattern of lower recurrence risks is also seen in essentially all types of relative for Australia. While the $95 \%$ CIs for these sets of data do overlap, there is a consistent trend for all categories of relative, and the overall OR for any affected

Table 2 Characteristics of Australian data

\begin{tabular}{llll}
\hline & Queensland & Victoria & Tasmania \\
\hline Probands & 575 & 941 & 321 \\
Males & 100 & 236 & 77 \\
Females & 475 & 705 & 244 \\
Female:male ratio & 4.75 & 2.99 & 3.17 \\
$\begin{array}{l}\text { Mean age } \\
\text { Mean pedigree size }\end{array}$ & 54.3 & 45.2 & 52.0 \\
$\begin{array}{l}\text { Probands with affected } \\
\text { relatives (\%) }\end{array}$ & 32 & & 34 \\
$\begin{array}{l}\text { Total affected relatives/total } \\
\text { relatives (\%) }\end{array}$ & $80 / 12709(0.63)$ & $81 /-$ & $63 / 9300(0.68)$ \\
\hline
\end{tabular}




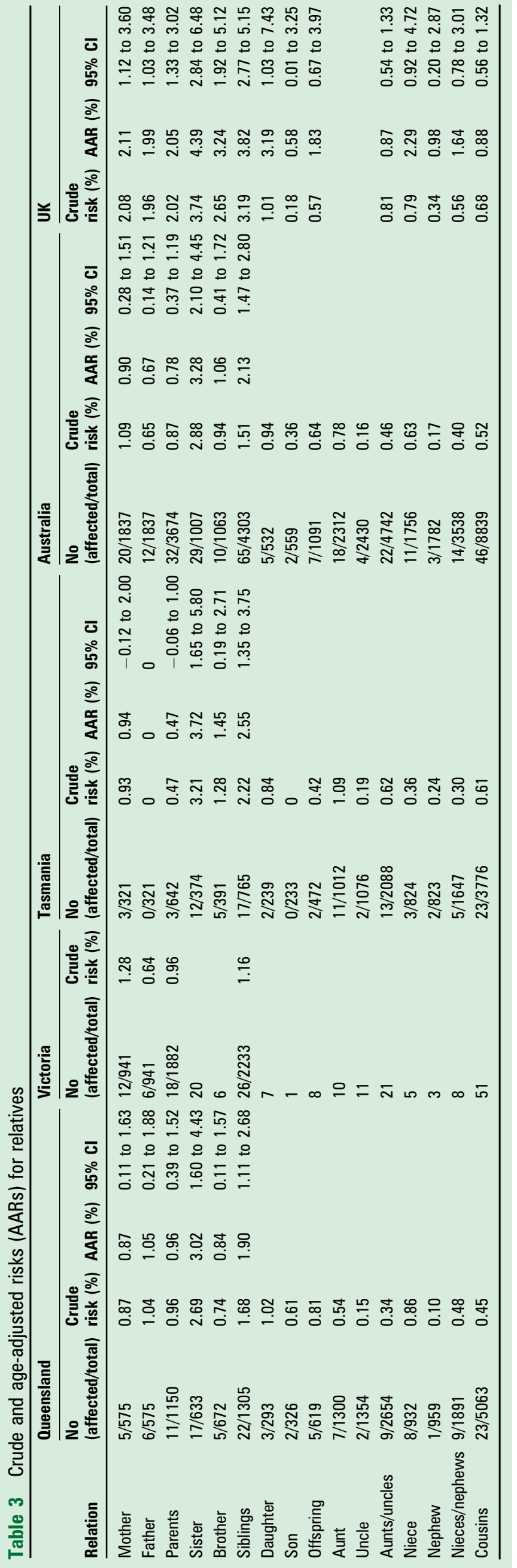

relative (Australia vs UK) was 0.65 ( $95 \%$ CI 0.52 to 0.82 ) with a $\chi^{2}$ value of 13.1 ( $p=0.00029$ ).

Estimates of $\lambda_{s}$ based on the crude sibling recurrence risks and quoted prevalence data for Australia were 35.6 (95\% CI 23.5 to 53.8) for Queensland, 13.8 (95\% CI 9.5 to 20.4) for Victoria and 18.2 (95\% CI 11.3 to 29.1) for Tasmania. The $\lambda_{\mathrm{s}}$ for Australia overall in this study was 21.2 (95\% CI 16.6 to 27.0 ).

\section{DISCUSSION}

This is one of the largest recurrence risk studies ever undertaken in MS and provides the first data for the southern hemisphere and first data for mid- to low-latitude regions: $27-43^{\circ}$ south. The recurrence risks calculated are lower than those previously reported for the northern hemisphere. These data provide accurate information specific to Australia and are therefore of value in counselling patients and their families regarding the likelihood of MS in relatives. The crude risk to offspring, which is usually the biggest concern for a person with MS, is $0.64 \%$. Although the lifetime, age-adjusted rate would be higher, this is still a reassuringly low level of risk. These findings, although from the southern hemisphere, may provide some guidance as to recurrence risks for populations in other parts of the world at similar latitude and with similar genetic/ethnic structures.

We have duplicated the findings of previous studies with regards to the higher risk to siblings when compared with both offspring and parents, with risks for siblings being close to double those for the other first-degree relatives. This is despite the same degree of genetic sharing (50\%). There are at least two possible explanations for this finding. The first is a degree of recessive inheritance with regards to the multiple susceptibility genes in MS. The second is an age- or time-specific environmental risk factor: siblings being closer in age are more likely to be exposed to the same temporal risks. The observed risk to cousins $(0.52 \%)$ was higher than for second-degree relatives $(0.43 \%)$. At first, this seems counter-intuitive, but this finding is identical to the crude results from the UK data where, following age adjustment, this pattern was reversed. The use of mothers in collecting family data may introduce a maternal line bias which could inflate estimates of more distant relatives, and this may be an explanation for the higher risk seen in cousins compared with second-degree relatives. ${ }^{22} 25$ We have not been able to age-adjust risks for more distant relatives or adjust for any changes in prevalence over time, and this limits our ability to interpret these findings.

The fact that the $\lambda_{s}$ for MS in Australia is directly comparable with figures for the northern hemisphere suggests that the degree of genetic susceptibility and therefore the underlying admixture of risk alleles are very similar in the two populations. Thus, we have found no evidence for significant genetic heterogeneity. This finding is consistent with analyses of genetic stratification within and between populations, which indicates that even quite disparate populations genetically have much more in common than previously speculated. ${ }^{26}$ The size of these cohorts and the variability of $\lambda_{s}$ in all reported studies make the interpretation of any potential gene-environment interaction difficult.

The similarity of $\lambda_{\mathrm{s}}$ across latitudes suggests that the observed decrease in population prevalence at lower latitudes is more likely due to changes in epigenetics and environmental risk factor exposure. This is a notion which has been previously suggested with regards to temporal changes in the incidence and gender profile of $\mathrm{MS}^{27}$ and the correlation between twin concordance and latitude. ${ }^{28}$ The most obvious environmental candidate to explain this difference in Australia is an increased 
exposure to sunlight and an associated reduction in relative vitamin $\mathrm{D}$ deficiency, for which there is growing evidence for an association in MS susceptibility ${ }^{29}$ and severity. ${ }^{30}$ Vitamin D is known to have immunological effects in $\mathrm{MS}$ and ${ }^{31}$ is effective in treating animal models of $\mathrm{MS},{ }^{32}$ and higher vitamin $\mathrm{D}$ levels are associated with a decreased risk of relapse. ${ }^{33}$

The higher $\lambda_{\mathrm{s}}$ for Queensland (35.5) does suggest the possibility that at the extreme of low environmental risk, genetic contributions to MS susceptibility may become more important. Plausible biological substrates for such an interaction have already been identified in CYP27B $1^{34}$ and vitamin $\mathrm{D}$ response elements influencing HLA-DRB1*1501 expression. ${ }^{35}$ However, the CIs for this single result are wide, and this figure may be artificially inflated through the use of a Queensland-wide prevalence figure. Previous studies have shown a twofold increase in prevalence between northern and southern Queensland, ${ }^{12}$ and the present study includes cases predominantly from southern Queensland as well as some from northern New South Wales where the population prevalence is higher still. ${ }^{13}$

In conclusion, the genetic contribution to MS risk in Australia is similar to that seen in the northern hemisphere. The fall in risk with increasing degrees of relatedness is directly comparable with previous studies. ${ }^{22}$ Data from recent genomewide association studies indicate that multiple genes play a role in MS susceptibility with HLA-DR*1501 carrying the predominant effect. ${ }^{36}$ As a consequence of lower environmental risk, Australian patients and their relatives can generally be reassured that the risk of recurrence within families is low, with the highest age-adjusted risk being $3.28 \%$ for sisters.

Acknowledgements We are grateful to the patients who enrolled in these studies and for the ongoing support of MS Australia. ANZgene consortium: M Bahlo (The Walter and Eliza Hall Institute of Medical Research, Parkville, Victoria, Australia), DR Booth (The Westmead Millenium Institute, Westmead, New South Wales, Australia), MA Brown (Diamantina Institute of Cancer, Immunology and Metabolic Medicine, Princess Alexandra Hospital, University of Queensland, Brisbane, Queensland, Australia; Botnar Research Centre, Nuffield Department of Orthopaedic Surgery, University of Oxford, Oxford, UK), SJ Foote (Menzies Research Institute, University of Tasmania, Tasmania, Australia), LR Griffiths (Genomics Research Centre, Griffith University, Queensland, Australia), TJ Kilpatrick (Howard Florey Institute, University of Melbourne, Melbourne, Victoria, Australia; Centre for Neuroscience, University of Melbourne, Melbourne, Victoria, Australia; Royal Melbourne Hospital, Parkville, Victoria, Australia), J Lechner-Scott (John Hunte Hospital, Hunter New England Health Service, Newcastle, New South Wales, Australia; Hunter Medical Research Institute, Newcastle, New South Wales, Australia), P Moscato (Hunter Medical Research Institute, Newcastle, New South Wales, Australia; Centre for Bioinformatics, Biomarker Discovery and Informationbased Medicine, University of Newcastle, New South Wales, Australia), VM Perreau (Centre for Neuroscience, University of Melbourne, Melbourne, Victoria, Australia), RJ Scott (John Hunter Hospital, Hunter New England Health Service, Newcastle, New South Wales, Australia, Hunter Medical Research Institute, Newcastle, New South Wales, Australia, Centre for Bioinformatics, Biomarker Discovery and Information-based Medicine, University of Newcastle, New South Wales, Australia), J Stankovich (Menzies Research Institute, University of Tasmania, Tasmania, Australia), GJ Stewart (The Westmead Millennium Institute, New South Wales, Australia), C Chapman (Barwon Health, Geelong, Victoria, Australia), M Marriot (Royal Melbourne Hospital, Parkville, Victoria, Australia), M Tanner (Royal Melbourne Hospital, Parkville, Victoria, Australia), N Tubridy (St Vincent's University Hospital, Dublin, Republic of Ireland), J Wiley (Howard Florey Institute, University of Melbourne, Victoria, Australia) (Chair).

\section{Competing interests None.}

Ethics approval Ethics approval was provided by the Griffith University HREC, Gold Coast Hospital HREC, Royal Hobart Hospital HREC and Melbourne Health HREC.

Provenance and peer review Not commissioned; externally peer reviewed.

\section{REFERENCES}

1. Naito S, Namerow N, Mickey MR, et al. Multiple sclerosis: associations with HL-A3. Tissue Antigens 1972;2:1-4.
2. Davenport CB. Multiple sclerosis from the standoint of geographic distribution and race. Arch Neurol 1922;8:51-8.

3. Ebers GC, Bulman DE, Sadovnick AD, et al. A population-based study of multiple sclerosis in twins. N Engl J Med 1986;315:1638-42.

4. Sadovnick AD, Baird PA. The familial nature of multiple sclerosis: age-corrected empiric recurrence risks for children and siblings of patients. Neurology 1988:38:990-1.

5. Schapira K, Poskanzer DC, Miller H. Familial and conjugal multiple sclerosis. Brain 1963:86:315-32.

6. Ebers GC, Sadovnick AD, Risch NJ. A genetic basis for familial aggregation in multiple sclerosis. Canadian Collaborative Study Group. Nature 1995;377:150-1.

7. Sadovnick AD, Ebers GC, Dyment DA, et al. Evidence for genetic basis of multiple sclerosis. The Canadian Collaborative Study Group. Lancet 1996;347:1728-30.

8. Risch N. Assessing the role of HLA-linked and unlinked determinants of disease. Am J Hum Genet 1987:40:1-14

9. Compston A. Genetic epidemiology of multiple sclerosis. J Neurol Neurosurg Psychiatry 1997:62:553-61.

10. De Jager PL, Jia X, Wang J, et al. Meta-analysis of genome scans and replication identify CD6, IRF8 and TNFRSF1A as new multiple sclerosis susceptibility loci. Nat Genet 2009;41:776-82.

11. Handel AE, Giovannoni G, Ebers GC, et al. Environmental factors and their timing in adult-onset multiple sclerosis. Nat Rev Neurol 2010;6:156-66.

12. Hammond SR, de Wytt C, Maxwell IC, et al. The epidemiology of multiple sclerosis in Queensland, Australia. J Neurol Sci 1987;80:185-204.

13. Hammond SR, English D, de Wytt C, et al. The clinical profile of MS in Australia: a comparison between medium- and high-frequency prevalence zones. Neurology 1988;38:980-6.

14. Poser CM, Paty DW, Scheinberg L, et al. New diagnostic criteria for multiple sclerosis: guidelines for research protocols. Ann Neurol 1983;13:227-31.

15. McDonald WI, Compston A, Edan G, et al. Recommended diagnostic criteria for multiple sclerosis: guidelines from the International Panel on the diagnosis of multiple sclerosis. Ann Neurol 2001;50:121-7.

16. Polman $\mathbf{C H}$, Reingold SC, Edan G, et al. Diagnostic criteria for multiple sclerosis: 2005 revisions to the "McDonald Criteria." Ann Neurol 2005:58:840-6.

17. Rubio JP, Stankovich J, Field J, et al. Replication of KIAA0350, IL2RA, RPL5 and CD58 as multiple sclerosis susceptibility genes in Australians. Genes Immun 2008;9:624-30.

18. Simpson S Jr, Pittas F, van der Mei AF, et al. Trends in the epidemiology of multiple sclerosis in Greater Hobart, Tasmania: 1951 to 2009. J Neurol Neurosurg Psychiatry 2011;82:180-7.

19. Risch N. Estimating morbidity risks with variable age of onset: review of methods and a maximum likelihood approach. Biometrics 1983;39:929-39.

20. Hammond SR, McLeod JG, Millingen KS, et al. The epidemiology of multiple sclerosis in three Australian cities: Perth, Newcastle and Hobart. Brain 1988:111:1-25.

21. Hader WJ, Elliot M, Ebers GC. Epidemiology of multiple sclerosis in London and Middlesex County, Ontario, Canada. Neurology 1988;38:617-21.

22. Robertson N, Deans J, Fraser M, et al. Multiple sclerosis in the north Cambridgeshire districts of East Anglia. J Neurol Neurosurg Psychiatry 1995:59:71-6.

23. Hensiek AE, Seaman SR, Barcellos LF, et al. Familial effects on the clinical course of multiple sclerosis. Neurology 2007;68:376-83.

24. Robertson NP, Fraser M, Deans J, et al. Age-adjusted recurrence risks for relatives of patients with multiple sclerosis. Brain 1996;119:449-55.

25. Sadovnick AD, Baird PA, Ward RH. Multiple sclerosis: updated risks for relatives, Am J Med Genet 1988;29:533-41.

26. Hensiek AE, Sawcer SJ, Compston DA. Searching for needles in haystacks-the genetics of multiple sclerosis and other common neurological diseases. Brain Res Bull 2003;61:229-34.

27. Alonso A, Hernan MA. Temporal trends in the incidence of multiple sclerosis a systematic review. Neurology 2008:71:129-35.

28. Islam T, Gauderman WJ, Cozen W, et al. Differential twin concordance for multiple sclerosis by latitude of birthplace. Ann Neurol 2006;60:56-64.

29. Munger KL, Zhang SM, O'Reilly E, et al. Vitamin D intake and incidence of multiple sclerosis. Neurology 2004;62:60-5.

30. Smolders J, Menheere P, Kessels A, et al. Association of vitamin D metabolite levels with relapse rate and disability in multiple sclerosis. Mult Scler 2008; 14:1220-4.

31. Mahon BD, Gordon SA, Cruz J, et al. Cytokine profile in patients with multiple sclerosis following vitamin D supplementation. J Neuroimmunol 2003;134:128-32.

32. Cantorna MT, Hayes CE, DeLuca HF. 1,25-Dihydroxyvitamin D3 reversibly blocks the progression of relapsing encephalomyelitis, a model of multiple sclerosis. Proc Natl Acad Sci U S A 1996;93:7861-4.

33. Simpson $\mathbf{S} \mathbf{J r}$, Taylor B, Blizzard L, et al. Higher 25-hydroxyvitamin D is associated with lower relapse risk in multiple sclerosis. Ann Neurol 2010;68:193-203.

34. ANZgene. Genome-wide associated study identifies new mulitple sclerosis susceptibility loci on chromosomes 12 and 20. Nat Gen 2009;41:824-96.

35. Ramagopalan SV, Maugeri NJ, Handunnetthi L, et al. Expression of the multiple sclerosis-associated MHC class II allele HLA-DRB1*1501 is regulated by vitamin D. PLoS Genet 2009:5:e1000369.

36. Wang JH, Pappas D, De Jager PL, et al. Modeling the cumulative genetic risk for multiple sclerosis from genome wide association data. Genome Med 2011;3:3. 


\section{Familial recurrence risks for multiple sclerosis in Australia}

C O'Gorman, S Freeman, B V Taylor, et al.

J Neurol Neurosurg Psychiatry 2011 82: 1351-1354 originally published online May 7, 2011

doi: 10.1136/jnnp.2010.233064

Updated information and services can be found at:

http://jnnp.bmj.com/content/82/12/1351.full.html

These include:

References This article cites 36 articles, 14 of which can be accessed free at: http://jnnp.bmj.com/content/82/12/1351.full.html\#ref-list-1

Email alerting Receive free email alerts when new articles cite this article. Sign up in service the box at the top right corner of the online article.

Topic Articles on similar topics can be found in the following collections

Collections

Immunology (including allergy) (1177 articles)

Multiple sclerosis (563 articles)

Notes

To request permissions go to:

http://group.bmj.com/group/rights-licensing/permissions

To order reprints go to:

http://journals.bmj.com/cgi/reprintform

To subscribe to BMJ go to:

http://group.bmj.com/subscribe/ 